\title{
Kierkegaard, pensador post-fundacional
}

\author{
Kierkegaard, post-foundational thinker
}

Maria José Binetti*

Resumen: Søren Kierkegaard se ha instalado en la historia de la filosofía como el pensador de una libertad puramente posible, capaz de crear su propio sentido y realidad. Lo posible, lo virtual, la potencia, constituyen para Kierkegaard el sustrato de la existencia, elemento, medio y fin de su acción libre y creadora. La determinación de la posibilidad infinita como origen y fundamento del ser supone la resignificación ontológica de lo real en su totalidad, en claro contraste con la vieja metafísica del acto perfecto y acabado. Las siguientes líneas intentarán leer a Kierkegaard en el horizonte post-fundacional de la ontología contemporánea como pensador de la inmanencia y contingencia radicales, cuya pura posibilidad de poder anticipa en muchos sentidos el nuevo giro especulativo del siglo XXI.

Palabras clave: Potencia, posibilidad, libertad, devenir, contingencia, fundamento

Abstract: Søren Kierkegaard is laid in the History of Philosophy as the thinker of a purely possible freedom, capable of creating its own meaning and actuality. The possible, the virtual, the potency constitute for Kierkegaard the substratum of existence, element, middle and end of its free and creative action. The determination of the infinite possibility as origin and foundation of being supposes the ontological resignification of actuality, in clear contrast with the old metaphysics of the perfect and complete act. The following lines will attempt to read Kierkegaard on the postfoundational horizon of contemporary ontology as a thinker of radical immanence and contingency, whose infinite possibility of power anticipates in many ways the new speculative turn of XXI Century.

* Doctora en Filosofía por la Universidad de Navarra (2004) e investigadora adjunta
del CONICET, Argentina. Desde el 2015 desarrolla su actividad en el Instituto
Interdisciplinarios de Estudios de Género de la Universidad de Buenos Aires. Su
trabajo de investigación se ha focalizado sobre el pensamiento de Søren Kierkegaard
en el contexto del idealismo alemán y el pensamiento francés contemporáneo. Dirección electrónica: mjbinetti@gmail.com 
Key-words: Potency, possibility, freedom, becoming, contingency, foundation.

\section{Introducción}

Lo posible, lo virtual, la potencia, lo que todavía no es, pero puede llegar a ser, emergen en el pensamiento contemporáneo como nuevo horizonte especulativo, disruptor del viejo paradigma fundacional sustancialista y operador de una post o des-fundamentación ontológica con decisivas implicancias éticas, políticas y religiosas. El nuevo horizonte especulativo quiebra el viejo paradigma metafísico a partir de, por lo menos, cuatro determinaciones principales. Éstas son, a saber: la superación de la trascendencia abstracta por la inmanencia concreta; la sustitución del acto perfecto por la potencia pura; el reemplazo de la sustancia auto-subsistente por el sujeto medial; y la linealidad causa-efecto por una totalidad auto-contenida de acciones recíprocas.

El pasaje del fundamento absoluto del ser -acto inmóvil, fin último y linealidad causal-al des-fundamento de lo puramente posible se resuelve en la contingencia radical de lo real, con la única certeza de su propia determinación autopoiética y la sola garantía de su juego creador. Autores como Slavoj Žižek, Catherine Malabou, Adrian Johnston, Markus Gabriel o Quentin Meillassoux, entre otros, coinciden en una ontología de la contingencia radical que ha perdido el apoyo de la sustancia perfecta para arriesgarse al juego indecidible de su propia acción libre y creadora, siempre mediada por la diferencia. Del paradigma de la trascendencia inalcanzable del acto perfecto y su mundo de esencias puras al paradigma de lo infinitamente posible y su indeterminación radical resulta una red auto-causal y auto-contenida de acciones recíprocas, desdoblada por la intra-acción de todos sus elementos en todos los demás y abierta a una complejidad dinámica indecidible, de efectos indeterminables.

La emergencia de lo posible como nuevo horizonte ontológico tiene una larga historia especulativa en la que Kierkegaard ocupa un lugar privilegiado. La confluencia kierkegaardiana con la nueva especulación se explica por la preeminencia de la posibilidad como categoría central de la existencia, elemento, medio y fin de su acción libre y creadora. No solo la libertad singular sino también el mundo objetivo y la divinidad misma deben su realidad al poder 
de lo posible. Kierkegaard ha ganado su lugar en la historia de la filosofía como el pensador de la posibilidad, a la cual apela tanto el movimiento existencial impulsado por él, como el nuevo horizonte especulativo post-fundacional. Autores como Slavoj Žižek, Michael O’Neill Burns, Alison Assiter o Steven Shakespeare leen a Kierkegaard como el ontólogo de la inmanencia y contingencia radicales en virtud de un des-fundamento puramente posible.

En lo que sigue, intentaremos analizar los principales conceptos kierkegaardianos que preludian el nuevo giro especulativo del siglo XXI.

\section{Schelling y el Ungrund potencial}

El pensamiento de Friedrich Schelling es considerado por muchos el inicio del existencialismo, en especial del kierkegaardiano, en referencia a la explícita oposición de Schelling al sistema de Hegel y su intento por superar las abstracciones racionales de este último en favor de la concreción existencial. Nos referimos particularmente al último período del pensamiento schellingiano, cuya principal divergencia con Hegel reside en la estructura totalizadora que éste le asigna al dinamismo reflexivo del concepto y aquel le niega en función de un resto irreductible, no-pensable y pre-pensable, exterior a la razón y constitutivo de la misma desde su posición trascendente. En otros términos, el último Schelling abandona el sistema de la identidad característico de su primer idealismo y se decide por un sustrato originario extra-racional y extra-actual, dispuesto fuera de la totalidad inteligible como Ungrund-desfundamento- oscuro, caótico y potencial, absolutamente indiferente e indeterminado, y por lo mismo capaz de todas las cosas.

La naturaleza de ese primer principio es volitiva y su deseo más profundo contiene su propia transparencia; se trata de un querer que anhela entender, pura potencia o poder presupuesto y sobrepuesto a la racionalidad derivada de él. La potencialidad oscura e indeterminada del Ungrund abismal es esencialmente libertad, y ella habilita y justifica para Schelling la existencia del mal y el error, explicados por la infinitud potencial del origen, capaz de todo. En el plano de la existencia concreta, cualquier acción, acto, juicio o concepto son irrevocablemente finitos, deficientes e incapaces de conceptualizar la 
infinitud del origen no-pensable y pre-pensable que subyace a todo pensamiento y funciona como ese resto inaprensible que lo sustenta.

La exterioridad des-fundante del pensamiento le permite al último Schelling distinguir entre la filosofía negativa y la positiva. La filosofía negativa es la ciencia de la razón, conocimiento meramente abstracto, ideal y representativo del quid sit, quidditas o esencia de las cosas; la filosofía positiva en cambio es la ciencia de lo existente, conocimiento concreto, abierto y progresivo del quod sit, quodditas o ser real. La primera se basa en la estructura $a$ priori de la razón; la segunda, en el a posteriori de la experiencia, recogida por Schelling a lo largo de la historia del mito y la revelación en una suerte de apercepción mítica primordial, siempre abierta a la emergencia del Ungrund primordial. Desde el punto de vista genético, la filosofía positiva de Schelling se inicia hacia 1833 con las lecciones de Múnich y caracteriza el período tardío de su pensamiento.

En 1841, Schelling fue convocado a la Universidad de Berlín por Guillemo IV de Prusia a fin de que su filosofía positiva conjurara los fantasmas hegelianos de la época y corrigiera el errático rumbo religioso sembrado por Hegel. La irrupción de Schelling en Berlín, decidido a desafiar el hegelianismo en el bastión hegeliano por antonomasia, constituyó un acontecimiento académico del cual participaron jóvenes hegelianos de izquierda como Friedrich Engels, Mijail Bakunin, Ludwig Feuerbach y Arnold Ruge, incluyendo al propio Kierkegaard. A pesar del entusiasmo inicial por las primeras lecciones de Schelling, sus incursiones en torno a la revelación histórica de lo divino parecen haber ahuyentado a los jóvenes hegelianos, quienes finalmente volvieron a la dialéctica hegeliana. ${ }^{1} \mathrm{La}$ semilla que el Schelling de Berlín sembró en ellos claramente no fue la positividad del mito, sino el esfuerzo por superar el registro abstracto del pensamiento en orden a concebir el devenir concreto de lo real. En la afirmación de la existencia por sobre el umbral de lo intelectivo reside la quintaesencia de la positividad schellingiana heredada por el existencialismo, el materialismo y, en última instancia, por el inconsciente psicoanalítico.

\footnotetext{
${ }^{1}$ Véase Norman, Judith y Welchman, Alastair (eds.), The new Schelling, London \& New York, Continuum, 2004, pp. 106-08.
} 
Según los apuntes tomados por Kierkegaard, ${ }^{2}$ las lecciones de Schelling en Berlín comenzaron por introducir la teoría de las potencias -Potenzenlebre o dinamología - como estructura del conocimiento y el ser. La doctrina de las potencias ya había sido propuesta por Schelling en Las edades del mundo -texto con más de 20 versiones todas inacabadas que su autor ensayó entre 1810 y 1833- en el sentido de una dialéctica de poderes sucesivos que se articulan progresivamente como: 1) la potencia negativa o sujeto, energía eterna que es pura materialidad, poder ser, posibilidad e indeterminación infinita de la cual surgen todas las cosas; 2) la potencia positiva u objeto, opuesta dialécticamente a la anterior en tanto que deber ser, necesidad, determinación y causa eficiente; y 3) la potencia positivo-negativa, síntesis reconciliadora y fin último del proceso donde la oposición indeterminación-determinación se resuelve en la auto-determinación libre y espontánea de la materialidad originaria. Las lecciones de Berlín recogen esa dialéctica ontológica y comienzan asentado la potencia como origen y elemento del pensamiento y el ser: Ungrund negativo, indeterminado y capaz de todas las cosas, cuya contradicción lo produce todo.

La afirmación de la potencia como des-fundamento de lo finito le permite a Schelling explicar el dinamismo libre, la contingencia del devenir y la existencia del mal, en virtud de un poder incondicionado que puede ser cualquiera de los términos opuestos o contradictorios. La naturaleza de esa potencia infinita es en sí misma libertad, querer, deseo y -explica Schelling-

en suprema y última instancia - no hay otro ser que querer. Querer es el ser originario y sólo con éste concuerdan todos los predicados del mismo: ausencia de fundamento, eternidad, independencia respecto al tiempo, autoafirmación. [...] todo lo efectivo (la naturaleza, el mundo de las cosas) tiene como fundamento actividad, vida y libertad, o, en palabras de Fichte, que no sólo el Yo lo es todo, sino que también, a la inversa, todo es Yo. La idea de convertir de pronto a la libertad en el Uno y Todo de la filosofía ha liberado al espíritu humano en general y no sólo en relación consigo mismo,

2 Véase Soren Kierkegaard's Papirer [en adelante Pap.], ed. P. A. Heiberg, V. Kuhr y E. Torsting, $2^{a}$ ed., 20 vols., København, Gyldendal, 1909-1948, III C 27, en XIII $253-$ 329 / Soren Kierkegaard Skrifter [en adelante SKS], ed. Niels Jørgen Cappelørn, Joakim Garff, Jette Knudsen, Johnny Kondrup y Alastair McKinnon, 28 vols., København, Gads Forlag, 1997-2013, Not11:1-40. 
y ha provocado en todas las partes de la ciencia un cambio más profundo y fuerte que el de cualquier revolución anterior. ${ }^{3}$

Esto es, la revolución de la libertad como posibilidad infinita.

Una vez desfondado el fundamento trascendente del acto puro y dispuesto en su lugar el Ungrund libre de lo posible, la cuestión radical de la filosofía ya no será ser o no ser, sino poder o no poder, elegir o no elegir lo sido. Con la afirmación de esa potencia infinita, Schelling inauguraba las Lecciones de Berlín y daba comienzo, según él mismo dice, a esa "bella época" del pensar en la cual "el espíritu se afianzó en la verdadera libertad frente a todo ser y se sintió autorizado a preguntar no ya ¿qué existe? sino ¿qué puede existir?”" Eso que puede existir o no existir es lo que la libertad quiere o no quiere hacer realidad. En tal posibilidad creadora reside el punto de partida del existencialismo en general y de Kierkegaard en particular.

\section{La emergencia de lo posible en el pensamiento de Kierkegaard}

Kierkegaard se introdujo en el pensamiento schellingiano por las lecciones universitarias de Hans L. Martensen durante el semestre invernal de 1838-1839, época de la cual datan las dos primeras referencias a Schelling de los Papeles kierkegaardianos. ${ }^{5}$ El entusiasmo por escucharlo en Berlín duró poco y a los dos meses y medio de iniciadas las Lecciones Kierkegaard vuelve a Copenhague con el objetivo de terminar O lo uno o lo otro. ${ }^{6}$ En sus cartas desde Berlín, Kierkegaard lamenta la impotencia y los sinsentidos de la teoría de las

\footnotetext{
${ }^{3}$ Schelling, Friedrich W. J., Investigaciones filosóficas sobre la esencia de la libertad humana y los objetos con ella relacionados, trad. H. Cortés y A. Leyte, Barcelona, Anthropos, 1989, pp. 146-149.

${ }^{4}$ Schelling, Friedrich W. J., Filosofía de la revelación, trad. J. Cruz Cruz, Cuadernos de Anuario filosófico 51, Pamplona, EUNSA, 1998, p. 110.

${ }^{5}$ Véase Kierkegaard, Søren, Pap. II A 31; III A 34 / AA:22; Not5:18.

${ }^{6}$ Los apuntes de Kierkegaard fueron tomados entre el 15 de noviembre de 1841 y el 4 de febrero de 1842, día en que abandonó el curso para regresar a Copenhague el 6 de marzo del mismo año. Semanas antes de abandonar Berlín, Kierkegaard le escribía a Emil Boesen y su hermano Pedro sobre los sinsentidos de Schelling, la poca claridad respecto de la filosofía positiva y la impotencia de sus potencias.
} 
potencias esbozada a través del mito y la revelación, lo cual no obsta el hecho de que él haya descubierto allí, más allá de la mitología, la fuerza infinita de lo posible de la que nace lo real.

Si vale afirmar con Michael O’Neill Burns que Kierkegaard llegó a Berlín buscando el concepto de «realidad» y que además, como el propio Kierkegaard confiesa, su pensamiento se estremeció de alegría cuando Schelling, "hablando de la relación entre filosofía y realidad, nombró la palabra realidad", 7 vale también precisar que lo encontrado en Berlín fue el concepto de potencia o posibilidad, cuyo Ungrund reduce lo real a lo que puede ser y resuelve la causalidad empírica en la indeterminación de la libertad. La dialéctica del poder será también la estructura de la ontología kierkegaardiana, originada en una infinita posibilidad de poder que desfunda tanto la conciencia objetiva como la subjetividad singular y, en última instancia, lo absoluto mismo. En otras palabras, el pensamiento de Kierkegaard despliega el juego libre de lo posible en una triple reflexión objetiva, subjetiva y absoluta, tal como intentaremos mostrar.

Inspirado en el Schelling de Berlín, Kierkegaard distingue el ámbito de la esencia -del quid sit o quidditas- reflejado por la conciencia representativa y objetiva, y el ámbito de la existencia - del quod sit o quodditas - actuado por el devenir efectivo. El primero es eterno, inmutable y necesario; el segundo, temporal, contingente y posible. Mientras que lo esencial permanece idéntico a sí mismo en su pura simplicidad abstracta, lo existente contiene cierto desdoblamiento reflexivo entre lo que podría no ser o ser de otro modo, aun en el caso de haber sido. Lo necesario no puede devenir; lo devenido es siempre posible y contingente aun siendo real, porque él contiene en sí mismo cierto desdoblamiento reflexivo y dialéctico que lo mantiene constantemente en la tensión de poder y no poder, ${ }^{8}$ es decir, en la infinitud de lo posible en su triple consistencia objetiva, subjetiva y absoluta.

El concepto de la angustia constituye el texto clave a la hora de precisar la naturaleza de lo posible en clara ascendencia schellingiana. El texto comienza

\footnotetext{
${ }^{7}$ Kierkegaard, Søren, Pap. III A 179 / Not8:33.

${ }^{8}$ Véase Soren Kierkegaards Samlede Varker [en adelante $S V^{2}$ ], ed. A. B. Drachmann, J. L. Heiberg, H. O. Lange, A. Ibsen y J. Himmelstrup, $2^{a}$ ed., 15 vols., Gyldendal, København, 1920-1936, IV 266 ss. / SKS 4, 274 ss.
} 
por remitir la posibilidad al dominio reflexivo de la libertad y, viceversa, por definir la libertad como "posibilidad para la posibilidad" (Mulighed for Muligheden), es decir, como la reflexión en sí de lo posible. El contenido de la posibilidad "consiste en poder"10, en una "infinita posibilidad de poder"11 (Den uendelige Mulighed af at kunne) activo y creador que convierte lo posible en "la más pesada de todas las categorías"12 (Muligheden er derfor den tungeste af alle Kategorier). La realidad es más liviana porque ella actualiza lo posible de manera finita, diseminada y sucesiva, mientras que la posibilidad en sí misma infinita y absoluta, sin otro origen más que su propia presuposición absoluta ni otro destino más que su propia creación. La posibilidad concreta, activa y ética es más pesada que cualquier realidad fáctica y Kierkegaard le asigna por eso un "valor educativo absoluto", ${ }^{13}$ capaz de infinitizar al sujeto libre y tensionarlo dialécticamente entre poder y no poder al mismo tiempo y bajo el mismo respecto.

El desdoblamiento reflexivo y dialéctico de lo posible, esto es, el hecho de superar la inmediatez simple de lo dado por la contraposición inmanente de poder y no poder a la vez, hace que la posibilidad sea siempre y en todo caso sujeto y objeto, cómo y qué, quod y quid, esto es, que sea autodeterminación libre y reflexiva. Lo específico de la posibilidad schellingiana-kierkegaardiana, aquello que le permite superar el orden necesario y simple de la esencia abstracta por el orden contingente y ambiguo de la existencia concreta, es la pura indeterminación de su origen resuelta en la dialéctica auto-determinación de su poder. Lo posible supera la determinación del orden formal por la autodeterminación efectiva: causa y efecto, sujeto y objeto de sí misma. El ámbito del quod sit, la existencia emerge de su indeterminación original y, cualquiera sea su acción positiva, conserva siempre la tensión dialéctica de lo posible como marca indefectible de su libertad ontológica.

\footnotetext{
${ }^{9}$ Kierkegaard, Søren, SV², IV 346 / SKS 4, 348.

${ }^{10}$ Kierkegaard, Søren, SV², IV 354 / SKS 4, 355.

${ }^{11}$ Kierkegaard, Søren, SV², IV 349 / SKS 4, 351.

${ }^{12}$ Kierkegaard, Søren, SV 2, IV 466 / SKS 4, 455.

${ }^{13}$ Kierkegaard, Søren, SV², IV 468 / SKS 4, 457.
} 
Esencia e existencia, conocimiento y acción son categorías de la libertad, modalidades de su despliegue auto-diferencial. Por eso para Kierkegaard "el devenir es el cambio de la realidad por la libertad", ${ }^{14}$

todo devenir sucede por la libertad y no deriva de la necesidad; nada de lo que deviene deriva de una razón, sino que todo lo que deviene procede de una causa. Toda causa se remonta a una causa libremente actuante. La ilusión de las causas hace que el devenir parezca necesario; su verdad consiste en que ellas, una vez que llegaron a ser, se remiten definitivamente a una causa libremente actuante. Ni siquiera la consecuencia de una ley natural explica en absoluto la necesidad del devenir, tan pronto como, en última instancia, la reflexión lleva al devenir. Lo mismo sucede con las manifestaciones de la libertad, cuando se considera su devenir, sin dejarse engañar por las manifestaciones. ${ }^{15}$

En estos términos, Kierkegaard sobrepone el orden contingente de la quodditas al orden necesario de la quidditas, pero no lo hace al modo de una yuxtaposición extrínseca y accidental, sino por una reducción inmanente al (des-)fundamento posible del ser, reflexivamente mediado y dialectizado en su propio poder. En última instancia, no hay otro ser que la libertad: concepto positivo de $A n$ sich, ${ }^{16}$ origen infundado, reflexivo y dialéctico de toda realidad y conocimiento. Y esto significa que toda sustancia finita, toda objetividad y subjetividad pertenecen a la intimidad del Ungrund potencial en su autodeterminación infinita.

En el caso de la conciencia objetiva, la posibilidad emerge en ella como el desdoblamiento o contraposición entre lo ideal y real, de lo cual surge la duda e incertidumbre de su posible adecuación o desajuste. Al igual que Schelling, Kierkegaard remite la duda a la "posibilidad"17 que des-funda la inmediatez irreflexiva y desdobla su poder en la vacilación de la impotencia. Estrictamente hablando, la última condición de posibilidad del conocimiento representativo

\footnotetext{
${ }^{14}$ Kierkegaard, Søren, SV², IV 270 / SKS 4, 277.

${ }^{15}$ Kierkegaard, Søren, SV², IV 267 / SKS 4, 275.

${ }^{16}$ Kierkegaard, Søren, SV², IV 416 / SKS 4, 410; véase también Schelling, Friedrich

W. J., Investigaciones filosóficas..., cit., pp. 148-149.

17 Véase Kierkegaard, Søren, Pap. IV B 1, p. 147.
} 
no reside en el entendimiento finito, sino en la fantasía infinita que produce la idealidad y de la cual dice Kierkegaard:

la imaginación es la reflexión que produce lo infinito; por eso el viejo Fichte tenía perfectamente razón al admitir que, incluso con respecto al conocimiento, la imaginación es la fuente de las categorías. El yo es reflexión y la imaginación es reflexión; ella produce un reflejo del yo que es su posibilidad. La imaginación es la posibilidad de toda reflexión; y la intensidad de este medio es la posibilidad de la intensidad del yo. ${ }^{18}$

La reflexión de la fantasía, en cuya infinitud se refleja la libertad, reduce la necesidad formal del intelectualismo representativo a la posibilidad efectiva de la existencia, lo cual supone la refundación del conocimiento objetivo por la acción libre. Y otro tanto vale para la subjetividad singular, cuyo devenir es igualmente reducido por Kierkegaard a la pura posibilidad de un poder absoluto, como veremos a continuación

\section{El devenir singular de lo posible}

Así como el An sich positivo de la libertad decide sobre el devenir empírico y la conciencia objetiva del mismo, él decide igualmente la constitución última de la subjetividad singular. En el caso de la conciencia subjetiva, ella refleja de manera auto-consciente la posibilidad infinita que lo real respira objetivamente por todas sus venas, y lo hace bajo el signo de la angustia: concepción subjetiva primera y fundamental de lo puramente posible.

El concepto de la angustia constituye un hito histórico-especulativo hacia la des-fundamentación posible de lo real, que el texto subraya en sus implicancias antropológicas, éticas y religiosas. Libertad y realidad comienzan, explica Kierkegaard, en la nada ontológica de lo posible, es decir, en su propia indeterminación que es efectivamente nada. La autoconciencia de esa nada original es lo que Kierkegard denomina angustia: una suerte de vértigo ante un abismo sin fondo en el cual no se teme caer por accidente sino más bien,

${ }^{18}$ Kierkegaard, Søren, SV2 XI 162 / SKS 11, 147. 
precisaba Schelling, ${ }^{19}$ saltar libremente. La angustia dura un instante, ${ }^{20}$ porque tal es el tiempo de su eternidad latente en el que se concentra la dialéctica infinita del poder. Esa "angustiante posibilidad de poder" 21 , tan oscura y abismal como el Ungrund schellingiano, es la conciencia del no-fundamento de la existencia.

A partir de esa angustiante posibilidad, el pensamiento kierkegaardiano prosigue una dialéctica potencial que traspasa desde la indeterminación inmediata de lo posible a su determinación negativa, para resolverse finalmente en la auto-determinación de lo absoluto. En efecto, si el elemento des-fundante de la angustia es la nada de lo posible, su des-fundación actual consiste en la negación afirmada como posición libre que Kierkegaard denomina también, usando la terminología teológica, "culpa", "caída" o "pecado". La misma negatividad que explica lo posible, se actualiza en lo real como acción libre que es en sí y por sí negación. Entre poder y no poder, lo que se decide es la libertad y los hechos indican que ella efectivamente no pudo, que su acción es negativa y contradictoria.

La caída de la libertad no tiene más explicación que ella misma, en la misma medida en que su salto no tiene más presupuesto que su propia posición retroactiva al des-fundamento. La máxima explicación que cabe a su respecto es la mostración de la dialéctica del poder y la irreductibilidad de su contradicción, que Kierkegaard expresa en estos términos: "la fuerza que le es dada a un hombre (en la posibilidad) es totalmente dialéctica, y la única verdadera expresión para la comprensión de sí mismo como posibilidad es que él precisamente tiene el poder para aniquilarse a sí mismo, porque él, aun si es más fuerte que todo el universo, sin embargo no es más fuerte que sí mismo."22 Justamente por no ser más fuerte que sí mismo, su acción libre es su propia negación, sin que nada más que lo posible pueda explicar su caída. La enfermedad mortal, por su parte, confirma la reducción de lo posible a impotencia y desesperación, con la esperanza de que la vida del espíritu vuelva a emerger de

\footnotetext{
${ }^{19}$ Véase Schelling, Friedrich W. J., Investigaciones filosóficas..., pp. 220-21.

${ }^{20}$ Véase Kierkegaard, Søren, SV², IV 387 / SKS 4, 384.

${ }^{21}$ Kierkegaard, Søren, SV2, IV 349 / SKS 4, 351.

22 Kierkegaard, Søren, Pap. V A 16 / JJ:209
} 
sus cenizas. ${ }^{23}$ La acción libre es, eo ipso, negación, caída, imposibilidad, y lo es por su propia des-fundamentación ontológica desplegada como dialéctica del poder.

A la posibilidad infinita del poder le sucede le negación infinita de la impotencia. Sin embargo, dialécticamente hablando, ambos términos no subsisten en su mera contradicción sino en una tercera instancia medial que es síntesis de ambos, o mejor, repetición del poder por el desdoblamiento concreto de la negación en el devenir real de lo absoluto. En y por su negatividad la libertad realiza efectivamente su poder como absoluto en esa acción que Kierkegaard denomina «fe». La acción de la fe emerge de su propia impotencia para negar su negatividad en un poder absoluto.

La fe es un movimiento reflexivo infinito, es decir, es el automovimiento de lo posible sobre sí mismo que retorna de su propia negación actual -la caída del pecado- a la afirmación de su poder infinito. Ella consuma el círculo de la autodeterminación positiva sin perder nunca ni la indeterminación de lo posible ni la negatividad efectiva de su dialéctica, pero superando la unilateralidad abstracta de ambos en la mediación concreta de la potencia absoluta. En palabras de Kierkegaard, la fe es "el movimiento de la infinitud en sí misma", ${ }^{24}$ la "inmediatez que sigue a la reflexión", ${ }^{25}$ de manera tal que "cuando la reflexión está completamente agotada -asegura él-comienza la fe." 26 Es entonces cuando lo puramente posible deviene real, conservando en su seno la tensión dialéctica entre la pura posibilidad indeterminada de lo an sich y la mera negatividad de lo for sich, ambas superadas en la segunda inmediatez mediada de lo absoluto.

La realiza una suerte de re-fundación o post-fundación absolutamente libre, que opera triplemente sobre la posibilidad objetiva, sujetiva y absoluta. En el caso de la conciencia objetiva, la fe refunda el conocimiento intelectual superando la linealidad causa-efecto en la circularidad de la acción recíproca, de manera tal que la posible adecuación cognoscitiva se resuelve en la auto-

\footnotetext{
${ }^{23}$ Kierkegaard, Søren, SV², XI 193 / SKS 11, 174.

${ }^{24}$ Kierkegaard, Søren, Pap. X1 A 481 / NB11:179.

${ }^{25}$ Kierkegaard, Søren, Pap. VIII ${ }^{1}$ A 649; X1 A 360 / NB4: 159; NB11:62.

${ }^{26}$ Kierkegaard, Søren, Pap. V A 28; véase también SV², IV 467; VI 174 / JJ:221; SKS 4, 456; 6, 151 .
} 
determinación de la libertad. La incertidumbre del conocimiento, insalvable desde el punto de vista intelectual, es así superada por la acción libre de la fe, porque "sólo con la libertad puedo salir de la duda en la que he entrado con la libertad." ${ }^{27}$ La cuestión gnoseológica se salva, para Kierkegaard, en la ontología, porque la verdad es en última instancia una cuestión de fe, es decir, de libre auto-determinación ontológica.

El conocimiento de la fe, a diferencia del conocimiento intelectual, es concreto, existencial o subjetivo, porque su órgano es la libertad y su acción consiste en "anular constantemente la incertidumbre correspondiente a la incertidumbre del devenir, que es doble: la nada del no-ser y la posibilidad destruida, que es al mismo tiempo el aniquilamiento de toda otra posibilidad."28 El movimiento reflexivo de la fe se desplaza de la indeterminación potencial a la determinación actual, de manera tal que él suprime la ambigüedad de lo posible en el devenir mismo de la existencia que nunca actúa de una vez y para todas, sino que está siempre llegando a ser. La acción absoluta de la fe no abandona jamás la posibilidad de la cual emerge, su actualidad se conserva en la dialéctica del poder y de aquí la eterna repetición que es la libertad kierkegaardiana.

En el caso de la subjetividad singular, la fe consuma la identidad dialéctica y sintética de los opuestos que la reflexión diferencia, a saber, entre la quidditas esencial y la quodditas existencial, el objeto y el sujeto de la acción libre. Kierkegaard explica al respecto que:

hay un "cómo" que tiene la propiedad de que cuando está dado, se da también el "qué", y es el "cómo" de la fe. Aquí la interioridad aparece en su culminación, la de ser a la vez la objetividad. Este es un desarrollo del principio de la subjetividad que, hasta dónde sé, no había sido hasta ahora agotado o realizado en tal sentido. ${ }^{29}$

La fe realiza la identidad posibilidad-actualidad, sujeto-objeto, existencia-esencia, forma-contenido, humanidad-divinidad, etc., en una síntesis

\footnotetext{
${ }^{27}$ Kierkegaard, Søren, Pap. IV B 13, 21.

${ }^{28}$ Kierkegaard, Søren, SV22 IV 273 / SKS 4, 281.

${ }^{29}$ Kierkegaard, Søren, Pap. X ${ }^{2}$ A 299 / NB14:121.
} 
dialéctica constituida como "lo tercero positivo"30, la "determinación intermedia" 31 o la "pura reciprocidad"32 de sí misma y lo otro, que ha superado las abstracciones dualistas por la auto-determinación diferencial y que se realiza de ese modo como sujeto absoluto.

La segunda inmediatez de la fe restituye la primera inmediatez posible, pero realizada como poder absoluto a través de la negatividad reflexiva. La identidad de la fe es la de un sujeto absoluto para quien todo es posible a cada instante ${ }^{33}$ y el cual "dispone a cada momento de 100000 posibilidades, sin que ninguna de estas posibilidades sea un milagro." $34 \mathrm{El}$ absoluto kierkegaardiano se concibe como sujeto en el punto de llegada de una reflexión por la cual el an sich posible de la libertad se afirma como potencia absoluta y se revela la metaposibilidad de lo finito. Él no es un fundamento actual pre-existente e independiente de la acción libre, sino el presupuesto reflexivo de la misma, solo real en la acción recíproca de aquella. En palabras de Michael O’Neill Burns, "la fe es la manera por la cual toda clase de totalidad ética o metafísica es reemplazada por la posibilidad como lo absoluto (cosa que podríamos igualmente llamar una absoluta contingencia), posibilidad que para Kierkegaard corresponde con la apertura del futuro." 35 El dinamismo de la fe no resulta extrínseco al absoluto, como si este fuera un objeto abstracto a inteligir o una realidad sustancial autosubsistente, sino inmanente a su reflexión subjetiva, como si este fuera la acción recíproca de un poder solo real en la acción recíproca que lo pone como infinitamente presupuesto.

$\mathrm{El}$ absoluto kierkegaardiano es pura potencia subjetiva, reflexionada en el no-ser de lo finito y recobrada desde allí como poder infinito. A lo largo de ese proceso, la posibilidad se mantiene como sustrato irreductible al acto finito, lo cual habilita su continua repetición creadora sin que eso suponga la merma de su infinitud. La actualidad de lo finito no disminuye la absolutidad del poder,

\footnotetext{
${ }^{30}$ Kierkegaard, Søren, SV² XI 143-144 / SKS 11, 29-30.

${ }^{31}$ Kierkegaard, Søren, SV 2 IX 126 / SKS 9, 111.

32 Kierkegaard, Søren, SV² IX 433 / SKS 9, 377.

33 Véase Kierkegaard, Søren, SV² XI 171-73 / SKS 11, p. 154-57.

34 Kierkegaard, Søren, Pap. IX A 412 / NB8:37.

35 O’Neill Burns, Michael, Kierkegaard and the Matter of Philosophy. A Fractured Dialectics, London, Rowman \& Littlefield, 2015, p. 96.
} 
porque el movimiento circular de la auto-determinación recupera reflexivamente su origen en cada acto. En palabras de Kierkegaard: "la omnipotencia constantemente se retoma a sí misma. La omnipotencia no consiste en la relación con otra cosa, porque no hay ninguna otra cosa con la cual relacionarse, no, ella puede dar sin ceder lo más mínimo de su poder, es decir, ella puede hacer independiente" 36 . Finitud e infinitud pertenecen así a un mismo proceso auto-relacional, cuya libertad consiste en la potencia de ser absolutamente otro en el seno de la pura reciprocidad.

El absoluto potencial se restablece a sí mismo en cada actualización y esto supone su apertura meta-posible -como posibilidad para la posibilidad-al devenir, pura indeterminación en la cual se justifica la indescernibilidad e imprevisibildad de lo futuro. En otras palabras, podríamos concluir con Michael O'Neill Burns en que para Kierkegaard "el concepto de Dios significa la absoluta posibilidad (o contingencia) que reside en el corazón de la realidad." 37

\section{La potencia kierkegaardiana como des-fundamento radical}

La posibilidad se revela en el trasfondo reflexivo del devenir como repetición ontológica a partir de lo cual lo inmediatamente dado resulta aquello mediado por su propia negatividad, contradiccion e incertidumbre. Lo posible opera para Kierkegaard como una suerte de desdoblamiento inmanente y original, que define la estructura dialéctica de todo el devenir. En el caso del devenir fáctico-universal y la conciencia objetiva que lo refleja, la vacilación entre poder y no poder, ser y no ser se expresa en la duda e incertidumbre del conocimiento intelectual. En el caos del devenir singular y la acción subjetiva que lo realiza, lo posible se refleja en la angustia de la decisión. En el caso de lo absoluto, lo posible se revela en la actualidad de la fe más allá de todo cálculo de probabilidad y previsión. Cualquieran sean los órdenes ontológicos apuntados por Kierkegaard, lo real se resuelve en lo posible y la posibilidad misma, en el des-fundamento de una potencia absoluta cuya indeterminación radical lo hace todo posible.

\footnotetext{
${ }^{36}$ Kierkegaard, Søren, Pap. VII ${ }^{1}$ A 181 / NB:69.

${ }^{37}$ O’Neill Burns, Michael, Kierkegaard and the Matter of Philosophy..., p. 101.
} 
La ontología kierkegaardiana se distingue del realismo ingenuo preidealista, entre otras cosas, porque su ser no se funda sobre el acto perfecto e inmóvil de la sustancia auto-subsistente, sino que se des-funda en el devenir de una posibilidad que necesariamente puede no-ser. En el origen y fin no es por lo tanto la perfección positiva de lo absoluto, sino su nada negativa y abismal. En el mismo sentido, la ontología kierkegaardiana se distingue de aquel porque su esencia no se conserva en la necesidad de lo eterno sino en la indeterminación de lo contingente, que por lo demás tampoco acontece como accidente extrínseco de esencias pre-determinadas, sino que actúa de manera inmanente reabsorbiendo la definición de la quidditas en lo posiblemente determinable.

La esencia de lo real es para Kierkegaard la posibilidad: origen inmanente, reflexivo y dialéctico del cual todo surge y al cual todo vuelve en su disolución por un movimiento de auto-determinación. Su negatividad media continuamente toda actualidad, y de allí el carácter imprevisible y novedoso de cada instante. Toda acción repite su origen potencial, lo retoma y autodiferencia de nuevo a lo largo de un devenir existencial siempre abierto a la espotaneidad creadora de aquello que no depende más que de su propia posición dialéctica. Tales son los términos en los cuales Kierkegaard es leído por el nuevo giro especulativo del siglo XXI como el pensador de la contingencia radical, heredero de un absoluto negativo e inmanente a la ruptura de la finitud. Repasemos, a modo conclusivo, las líneas generales en las que Kierkegaard es leído hoy por la nueva ontología.

Slavoj Žižek, ${ }^{38}$ uno de los grandes teóricos de la nueva especulación, lee a Kierkegaard en continuidad con el idealismo como el pensador de la nocoincidencia del todo consigo mismo, es decir, de la negatividad, inconsistencia y desajuste de lo absoluto, cuya permanente contradicción consigo mismo despliega la dialéctica insuperable de la finitud. En lugar de un fundamento trascendente que regule la totalidad de las cosas, lo real explicita la diseminación diferencial de una potencia infinita en continua apertura y transformación. También Gilles Deleuze y Felix Guattari leen a Kierkegaard como el pensador de la inmanencia y el devenir radicales: "Kierkegaard muestra que el plano del infinito, lo que él llama el plano de la fe, debe devenir puro plano de inmanencia

38 Žižek, Slavoj, The Parallax View, Cambridge, MIT Press, 2006, pp. 75-80. 
que no cesa de dar inmediatamente, de restituir, de registrar lo finito." ${ }^{39} \mathrm{El}$ caballero de la fe coincidiría entonces con el hombre del devenir, en la misma medida en que el devenir coincide para Deleuze y Guattari con el movimiento de la infinitud sobre sí misma, es decir, con la auto-determinación de lo inmediato indeterminado, siempre resuelto en la posible novedad del devenir. Muy próximo a la lectura deleuzeana se pronuncia Steven Shakespeare, para quien la trascendencia kierkegaardiana no debe ser inteligida como otro mundo más allá, sino como la transformación de este mundo en "el acontecimiento de lo incondicionado en lo finito" 40 en tanto repetición efectiva de lo posible en lo real. Shakespeare habla en este sentido de una trascendencia horizontal o inmanente, donde lo absoluto emergen en la reflexión misma de la finitud como su novedad radical.

Alison Assiter, por su parte, comparte la interpretación kierkegaardiana de una ontología procesual auto-determinada por la pura potencia, cada uno de cuyos actos refluyen sobre su poder inagotable. La fuente última de la posibilidad kierkegaardiana consiste para Assiter en el Schelling del Ungrund oscuro y abismal, que anhela darse a luz a sí mismo y vuelve a parirse una y otra vez sin agotar nunca la infinitud de su potencia. Para una ontología del proceso como la schellingiano-kierkegaardiana no existe, afirma Assiter, un Dios omnisciente y omnipresente al modo de una trascendencia autosubsistente, sino más bien "Dios sería el poder que pone el proceso en movimiento" 41 : la potencia primera, auto-activa inmanente al movimiento mismo como sujeto último de todo devenir.

Por último, la lectura de Michael O’Neill Burns coloca a Kierkegaard en la antesala del materialismo dialéctico del siglo XXI, tanto por la reducción del acto a la potencia como por la inmanencia de lo posible y la negatividad de lo absoluto, materializada en el desacuerdo de todas las cosas y la permanente apertura de lo nuevo. En lugar de una totalidad acabada y cerrada sobre sí

${ }^{39}$ Deleuze, Gilles y Guattari, Félix, Mil mesetas. Capitalismo y esquirofrenia, trad. José Vázquez Pérez, Valencia, Pre-textos, 2002, p. 283.

${ }^{40}$ Shakespeare, Steven, Kierkegaard and the refusal of transcendence, New York, Palgrave Macmillan, 2015, p. 15.

${ }^{41}$ Assiter, Alison, Kierkegaard, Eve and Metaphors of Birth, London \& New York, Rowman \& Littlefield, 2015, p. 128. 
misma, Kierkegaard afirma el no-todo de la existencia en continuo devenir y transformación. Así como la existencia imposibilita su clausura, el absoluto mismo reyecta su objetivación extrínseca para desdoblarse reflexivamente en la no-absolutivdad de lo real. La negatividad de lo no-absoluto es la fragilidad de lo finito, su inconsistecia y fractura, y no hay nada más allá de esa incansable ruptura de la finitud, ni nada más acá de su permanente virtualidad.

La reducción del fundamento actual al des-fundamento posible constituye la quintaesencia especulativa del pensamiento kierkegaardiano, asumida y continuada por el último giro de la filosofía. Inmanencia, negatividad y posibilidad son los parámetros de una ontología radical, acostumbrada al desgarramiento esencial de lo (no-)absoluto. Al hilo de esta nueva interpretación, Kierkegaard es leído en continuidad con el idealismo absoluto y en el preludio de un neo-realismo post-teológico, cuya divinidad resulta tan virtual y contingente como el mundo donde acontece. Y paradójicamente, en esa sublime fragilidad despunta su potencia absoluta.

\section{Bibliografía}

Assiter, Alison, Kierkegaard, Eve and Metaphors of Birth, London \& New York, Rowman \& Littlefield, 2015.

Deleuze, Gilles y Guattari, Felix, Mil mesetas. Capitalismo y esquizofrenia, trad. José Vázquez Pérez, Valencia, Pre-textos, 2002.

Gabriel, Markus y Žižek, Slavoj, Mythology, Madness and Laughter. Subjectivity in German Idealism, New York, Continuum, 2009.

Hegel, Georg W. F., Werke in zwanzig Bänden, 20 vol., Frankfurt, Suhrkamp, 1969.

Kierkegaard, Søren, Søren Kierkegaard Skrifter [SKS], ed. Niels Jørgen Cappelørn, Joakim Garff, Jette Knudsen, Johnny Kondrup, Alastair McKinnon, 28 vols., København, Gads Forlag, 1997-2013.

Soren Kierkegaards Samlede Varker [SV'], ed. A. B. Drachmann, J. L. Heiberg, H. O. Lange, A. Ibsen, J. Himmelstrup, $2^{\mathrm{a}}$ ed., 15 vols., København, Gyldendal, 1920-1936. 
Soren Kierkegaard's Papirer [Pap.], ed. P. A. Heiberg, V. Kuhr y E. Torsting, $2^{a}$ ed., 20 vols., København, Gyldendal, 1909-1948.

1842), trad. Óscar Parcero Oubiña, Madrid, Trotta, 2014.

Apuntes sobre la Filosofía de la Revelación de F. W. J. Schelling (1841-

Norman, Judith y Welchman, Alastair (eds.), The new Schelling, London \& New York, Continuum, 2004.

O'Neill Burns, Michael, Kierkegaard and the Matter of Philosophy. A Fractured Dialectics, London, Rowman \& Littlefield, 2015.

Schelling, Friedrich W. J., Las edades del mundo, Madrid, Akal, 2002.

Filosofía de la revelación, trad. J. Cruz Cruz, Cuadernos de Anuario filosófico 51, Pamplona, EUNSA, 1998.

Investigaciones filosóficas sobre la esencia de la libertad bumana y los objetos con ella relacionados, trad. H. Cortés y A. Leyte, Barcelona, Anthropos, 1989.

Shakespeare, Steven, Kierkegaard and the refusal of transcendence, New York, Palgrave Macmillan, 2015.

Žižek, Slavoj, Absolute Recoil. Towards A New Foundation of Dialectical Materialism, London \& New York, Verso, 2014.

The Parallax View, Cambridge, MIT Press, 2006.

Recibido: 11/2017; aceptado: 02/2018 